\title{
Condiciones del desplazamiento forzado de mujeres en mesoamérica
}

\section{Manuela Camus ${ }^{1}$ \\ Bernadette Eguía ${ }^{2,3}$}

'Departamento de Estudios

Sociourbanos de la Universidad

de Guadalajara, México. Correo

electrónico:

manuelacamus@gmail.com

${ }^{2}$ ITESo, México.

Correoelectrónico:

bernieguiaornelas@gmail.com

${ }^{3}$ Ambas autoras coincidieron en

este espacio de atención a

migrantes en tránsito y quisieron

visibilizar la situación de las

mujeres rescatando las

especificidades de su problemáti-

ca con la intención de continuar

esta labor. Agradecen a FM4 por

su apoyo.

\begin{abstract}
Resumen
Este texto se centra en las experiencias de las mujeres centroamericanas dentro de la diáspora masiva hacia el sobrevivir huyendo de las violencias sistemáticas de género y la situación de extrema precariedad en sus países de origen. Violencias que se extienden en el tránsito por el territorio mexicano. Se detiene en las mujeres que llegan al Centro de Atención del Migrante de FM4 Paso Libre en Guadalajara donde reciben acompañamiento psicológico y nos permiten conocer las tortuosas condiciones de su camino a través de México.
\end{abstract}

Palabras clave: mujeres en desplazamiento forzado, sobrevivencia, cuerpos mercancía, feminicidio y femigenocidio.

\begin{abstract}
This text focuses on the survival experiences of Central American women within the massive diaspora who are fleeing from a systematic gender of violence and extremely precarious situations in their countries of origin. Such violence persists during their passage through
\end{abstract}




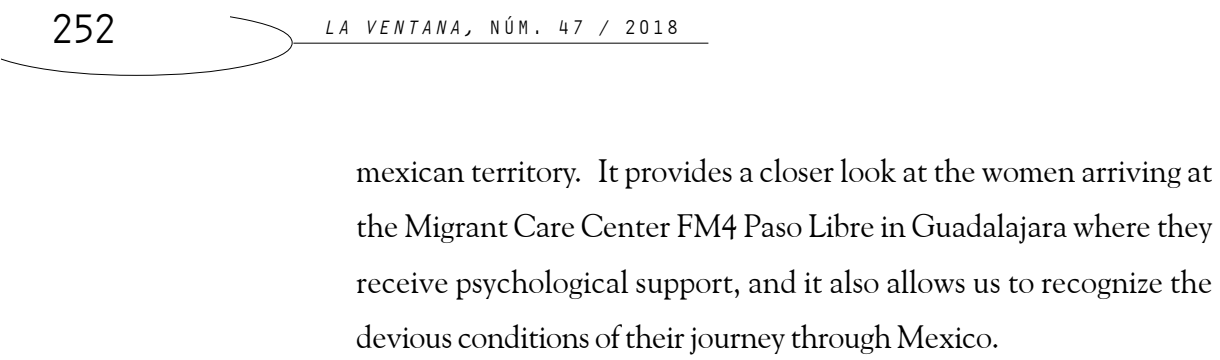

Keywords: Women in forced displacement, survival, commodity bodies, feminicide and femigenocide

RECEPCIÓN: 28 DE MARZO DE 2017/ACEPTACIÓN: 12 DE JUNIO DE 2017

Este escrito rescata la información sobre el dramático paso por México de mujeres centroamericanas sin documentos migratorios y de mujeres mexicanas en la intención de llegar a Estados Unidos. Se centra en aquellas que pasaron por el Centro de Atención a Migrantes CAM- de FM4 Paso Libre en la ciudad de Guadalajara donde, a lo largo del 2016, se puso en marcha un programa específico para su asistencia por parte del Instituto Municipal de las Mujeres. El mismo consistió en entregar una mochila especial con productos dirigidos a ellas (toallas sanitarias, pastilla del día siguiente, un condón femenino, gel antibacterial, agua oxigenada...), y ofrecerles un acompañamiento psicológico.

La recogida de la información es limitada porque responde a la urgencia de los flujos de los migrantes en tránsito que un día llegan, son asistidos, descansan mínimamente y se van. Así sucede también en el caso de las mujeres. En ellas, el proceso de atención 
psicosocial se registró en un cuaderno y se elaboró una pequeña base de datos con sus características sociodemográficas, así como la situación concreta que traían. Como se verá, el programa cubrió a 77 mujeres. Las conversaciones fueron intensas y, a pesar de que no se grabaron por ser parte de un proceso terapéutico, alimentan la elaboración de este texto. Aunque el número de mujeres no alcanzan ni el 5\% con respecto al volumen de hombres, son relevantes porque nos destapan historias y problemáticas invisibilizadas. Queremos al menos ofrecer algunas de sus huellas y esos ecos fugaces de tantas mujeres en el tránsito por el territorio mexicano buscando sobrevivir.

\section{Mujeres en fuga}

El paso por el territorio mexicano de los migrantes en tránsito sin los papeles de migración precisos a través del territorio mexicano es tortuoso. Tal falta, reconocida como administrativa por la legislación mexicana, es motivo de persecución, privación de libertad y posible deportación. Esto, junto con el refuerzo de los controles migratorios a lo largo de México, obliga a los migrantes a moverse en la clandestinidad facilitando el maltrato y abusos extremos por delincuentes y el crimen organizado, por la población local, y paradójicamente, por las propias fuerzas de seguridad y migración mexicanas. Aparte dentro del argot de las instituciones que se dedican al apoyo de estos migrantes irregulares es una "catástrofe humanitaria”, pero hay que ir más allá en las explicaciones, dada la responsabilidad de los Estados-nación implicados en el proceso in- 


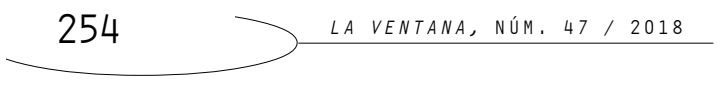

${ }^{4}$ Médicos Sin Fronteras señala que ha documentado un "patrón de desplazamiento violento, persecución, violencia sexual y repatriación forzada muy similar al que se puede encontrar en los conflictos armados más agudos del mundo" (2017: 4).

${ }^{5}$ Con el término bionecropolítica incorporamos simultáneamente los dispositivos biopolíticos en la generación y regulación de cuerpos dóciles (Foucault, 2007) y la necropolítica de administració

n de la muerte (Mbembe, 2011). Esta última se dirige no ya a los cuerpos individuales, ni a la población, sino a las multitudes y su acción es más indiscriminada. Lo hacemos así mientras se esclarece el funcionamiento de estas dimensiones del poder en la migración de tránsito.

6 En este texto escribimos Centroamérica como metonimia de los países de Guatemala, El Salvador y Honduras.

${ }^{7}$ Tomando las cifras sobre detenciones por parte del Instituto Nacional de Migración (INM), Willers (2016) obtiene que del total de las personas centroamericanas deportadas a sus países, el $15.6 \%$ eran mujeres y el $84.4 \%$ hombres. cluso a nivel mundial. ${ }^{4}$ Esta situación nos remite al funcionamiento de tecnologías de poder bionecropolíticas dirigidas sobre estos cuerpos desechables dentro de extensos regímenes de deportación (Peutz y De Genova, 2010) que filtran quienes pueden o no pasar las fronteras nacionales y en qué condiciones, quienes han de quedar en el nomadismo y en el abandono, desocializados, sin derechos. $^{5}$

Según el Alto Comisionado de las Naciones Unidas para los Refugiados (ACNUR), cada año atraviesan el territorio mexicano cerca de 500000 migrantes con destino es Estados Unidos. La mayoría proceden de Centroamérica (Médicos Sin Fronteras, 2017: 4). ${ }^{6}$ Según diferentes fuentes las mujeres pueden ser entre el 15\% y el 30\%. ${ }^{7}$ Como bien dice Amarela Varela (2017: 2), esta indefinición por no contarse con estadísticas concretas, correctas y verificables propias de regímenes de control biopolítico representa

un espejo perverso de las formas en que son gestionados los movimientos de personas... de tal suerte que, como en muchas otras dimensiones de las migraciones que nos ocupan, los estudiosos de este fenómeno caminamos a tientas. No podemos afirmar cuántos migrantes intentan el éxodo, cuántos lo logran, cuántos desaparecen en el intento. 


\section{Cuerpo de mujer, feminicidio y femigenocidio}

La dificultad de estimar los números de la diáspora se vincula con los dispositivos que facilitan la desechabilidad humana. Actualmente "las y los centroamericanos huyen de la violencia del mercado neoliberal que infringió todos los ámbitos de su vida cotidiana y generalizó el uso de la violencia, sobre todo contra las mujeres, ante gobiernos omisos y cómplices" (Varela, 2017: 3). Esta precarización extrema se acentúa en las mujeres por la violencia sistemática de género que existe en todo nivel y en todas las relaciones sociales (Colectivo de Apoyo para Personas Migrantes, 2015).

La salida de las mujeres de Centroamérica se produce por los precarios empleos en las industrias maquiladoras, en el comercio o en el servicio doméstico, si es que pueden alcanzarlos. Además experimentan una "muerte en vida" por ser mujeres en un contexto criminal de violencia machista y patriarcal que se extiende como un continuo de terror (Varela, 2017: 3). Las violencias feminicidas son de carácter físico, emocional, sexual, material o simbólico (Carcedo, 2010). En algunos casos suceden todas juntas, y este continuo estructural de violencia se mantiene en el tránsitoéxodo-fuga hacia, supuestamente, una vida más digna o simplemente de sobrevivencia. ${ }^{8}$

${ }^{8}$ La categoría "feminicidio" frente a femicidio incorpora considerar, más allá del asesinato de mujeres sistemático y cruel, unas condiciones históricas y prácticas sociales que permiten atentados violentos contra la integridad, salud, libertades y vida de mujeres y niñas previos a una eventual muerte, donde además hay responsabilidad del Estado (Lagarde, 2008).

El cuerpo de la mujer ha sido históricamente expropiado a través de su sexualidad, de la maternidad, de las labores domésticas y del cuidado. Pero al contextualizar hoy este acto de 
dominación, llama la atención la actualización del mercado del cuerpo. La formulación de Sayak Valencia (2010) sobre el capitalismo gore ayuda a explicar el porqué de este proceso. El género de cine gore de violencia extrema, donde prima el derramamiento de sangre y vísceras explícito e injustificable, se habría trasladado a nuestra realidad regida por el narcotráfico y otras empresas entre lo legal y lo ilegal. En esta lógica, el cuerpo humano se convierte en mercancía y se introduce a circuitos de ganancia y de poder, es un negocio rentable. El cuerpo se coloca así en el centro explicativo de las violencias como herramientas de necroempoderamiento neoliberales. Este eje de acumulación en la actual bioeconomía de hiperconsumo genera un régimen predatorio donde los cuerpos y las vidas se suman en una condición ultraprecarizada.

El capitalismo gore y su necropolítica opera desde el Estado, pero también se desancla del mismo apareciendo otros actores, otras máquinas de guerra como las que vemos en los escenarios centroamericanos y mexicanos que cruzan los migrantes en tránsito. En estos escenarios en estado de excepción se traslapan diferentes soberanías además de las instancias estatales. Los miembros de maras -pandillas o clicas-, grupos criminales, compañías de seguridad privadas, cuerpos de seguridad públicos... ejercen el poder y el lucro sobre sus iguales mediante la aplicación de formas de control y administración de la población. La lucha por la sobrevivencia se acciona contra los semejantes más vulnerables en una suerte de canibalismo social. Sus integrantes son parte del surgimiento de una clase criminal que Sayak Valencia (2010) identifica como "su- 
jetos endriagos" y que se representan y actúan desde la supremacía masculina violenta, siendo los encargados de capitalizar los cuerpos. Desde la paralegalidad se refuerzan los sustentos epistemológicos del capitalismo: la rentabilidad y el éxito emprendedor, los estereotipos de género y de macho proveedor y violento. Con ellos, el orden clasista es reinterpretado, así como los postulados humanistas.

Los grupos masculinos armados son organizaciones heterogéneas y metamórficas que se han territorializado en zonas de hiperurbanización (como en las principales ciudades de Centroamérica o México). Dueños del poder de matar, estas fratrías dejan de lado la identidad del trabajador sacrificado y proveedor, y tienden a desarrollar otras dimensiones de la virilidad a través de la autoafirmación por la violencia y la competencia masculinista. Como resultado se muestran agresivos hacia las mujeres, mientras continúan manifestándose como conquistadores de mujeres y hacedores de hijos.

Estos colectivos e individuos permiten comprender el incremento de feminicidios en Centroamérica. A pesar de los avances en materia de marcos legales para penalizar la violencia contra la mujer, Honduras, El Salvador y Guatemala se encuentran en una escalada de muertes violentas de mujeres (Carcedo, 2010). Se trata de asesinatos sin contexto bélico, con violaciones, crueldad y saña, que hasta ahora resultan impunes porque ha sido característica la desidia, la indiferencia, la negligencia en la recogida sistemática de las pruebas por parte de autoridades competentes. 
Los crímenes sexuales son expresiones de una estructura simbólica profunda, de un imaginario de género compartido que busca expresar poder y expropiar a la víctima de su voluntad y del control sobre su espacio-cuerpo (Segato, 2016). Pero ante manifestaciones como las que muestran estos grupos, Segato propone distinguir feminicidio y femigenocidio.

Según la autora, femigenocidio se refiere a prácticas bélicas no convencionales como las señaladas que expresan su poder sobre cuerpos vulnerables y frágiles como los de mujeres y niños, y no a crímenes perpetrados en la intimidad del universo doméstico sobre víctimas cercanas al abusador. Los agresores se apropian del cuerpo femenino en un espacio abierto, público, en una exhibición de dominio y de destrucción moral del enemigo. Es una agresión sexualizada que utiliza el cuerpo de la mujer como bastidor o soporte. El objetivo es romper los tejidos sociales comunitarios donde las mujeres son su centro de gravedad. En el caso que tratamos, el empujarlas al desplazamiento es enviarlas a la intemperie y la desprotección, otra modalidad de la "precarización de la vida vincular" (Segato, 2016: 100). Este proceso se rela-

${ }^{9}$ Escenarios de feminicidio son "los contextos socioeconómicos, políticos y culturales en los que se producen o propician relaciones de poder entre hombres y mujeres particularmente desiguales y que generan dinámicas de control, violencia contra las mujeres y feminicidio que adoptan o incluyen características propias" (Carcedo, 2010: 15). Los escenarios históricos del feminicidio se encuentran en las relaciones de pareja, la familia, el acoso sexual, el ataque sexual y el comercio sexual. ciona con los nuevos escenarios y lógicas del feminicidio, como el de la trata, la explotación sexual, las mafias, las maras, la venganza entre hombres ejecutada sobre el cuerpo de las mujeres, algunos de ellos articulados y facilitados con estas dinámicas migratorias forzadas (Carcedo, 2010). ${ }^{9}$ 
Desde inicios de siglo los feminicidios aumentan significativamente por encima de los homicidios de hombres, sin embargo muestran nuevas formas en las relaciones desiguales de género al aparecer los cuerpos fuera del espacio doméstico (Carcedo, 2010: 40-42). Como vemos, las autoras citadas en este apartado conectan las bionecropolíticas contemporáneas con el género y el patriarcado exacerbado. ${ }^{10}$

${ }^{10}$ Hay que ver cómo aplican o no estos marcos en el conjunto de violencias sufridas por las mujeres en sus lugares de origen y en la diáspora. Ver también cómo resisten sus cuerpos y cómo son mujeres con estrategias, agencia y vitalidad.

\section{Mujeres y madres}

La presencia en este éxodo de mujeres diversas (madres solteras, unidas, separadas, con hijos de uno o diferentes hombres, jóvenes, adultas...) es activa y consciente. No se las puede considerar como acompañantes secundarias de los hombres. Ellas son las que toman la decisión de huir, que es también de desear y aspirar, pero hasta donde pueden lo hacen con redes que las apoyan.

El proceso migratorio no afecta solo a las personas migrantes sino a su entorno. En el caso de las mujeres su movilidad exige reestructurar la organización de todo un conjunto de personas por el mandato social que tienen sobre el cuidado de otros. Por ello la salida de las mujeres cuenta con actores varios, pero sobre todo con algunos en la sombra como son las abuelas, tías, hermanas, que son parte activa del proceso y que lo facilitan.

Buena parte de las mujeres en fuga son madres. "La mayor parte de las mujeres migrantes centroamericanas son jóvenes, madres de 
${ }^{11}$ En 2006 Díaz Prieto y Kuhner (2014:

42) encontraron que el $94 \%$ de las mujeres entrevistadas se separaron de sus hijos al migrar y la mitad de ellas dejó a menores de cinco años de edad. Habría que poner al día estos datos y ver si hubiera aumentado la salida de familias y/o mujeres con hijos. niñas y niños, que viven sin una pareja, son mujeres empleadas que requieren aumentar sus ingresos para atender a sus hijos" (Díaz y Kuhner, 2014: 42). ${ }^{11}$ Ellas tienen un ideal de maternidad y de sacrificio por los hijos muy fuerte y, en su experiencia migrante, se ven inmersas en el debate entre ser una "buena madre", que tiene que adoptar esta decisión extrema de salir del hogar y el estigma social de "mala madre" cuando tienen que dejar a sus hijos al cuidado de otra personas, malinterpretándose como abandono, o llevándolos consigo en un camino incierto y peligroso.

Los estudios que inciden sobre las cadenas globales de cuidado nos permiten observar estos arreglos. Pero también hay que dimensionar los niveles de desarreglo.

Ya está ampliamente documentado el hecho de que el grupo familiar y la familia extendida están tan desarticuladas por la globalización que ya las redes femeninas no logran cumplir el papel tradicional en cuanto al cuidado de los hijos y otros dependientes de las mujeres que van a trabajar a la ciudad o bien a otro país. Se puede decir que ya no hay suficientes abuelitas ni tías para resolver esta necesidad sin los traumas cada vez mayores que se están viviendo, como dejar la prole bajo la total responsabilidad de una hermana mayor, aunque ésta sea una niña de 10 años, o como la separación entre hermanas/os (Castro, 2010: 113-114). 
Entre las motivaciones combinadas de las mujeres a migrar seguramente se encuentra el que los hombres no logran cumplir su papel de protectores proveedores y se desresponsabilizan. Son ellas las que tienen que hacerse cargo de una manera cada vez más generalizada de estas tareas. Se trataría de esos efectos venenosos de los dispositivos bionecropolíticos que permean las cotidianidades y facilitan procesos de precarización y producción de cuerpos disciplinados y desechables a la vez.

\section{Mujeres en el tránsito}

En el camino por territorio mexicano el continuo de violencias feminicidas se acentúa:

La especificidad del cuerpo de mujer como terreno de riesgo expone a la migrante a una situación constante de acoso, agresiones, violaciones y al mismo tiempo el cuerpo femenino representa un recurso potencial para la sobrevivencia y para el cumplimiento de su proyecto de vida (Castro, 2010: 39).

Las estructuras desiguales de poder y género facilitan que al alejarse las mujeres del ámbito doméstico se hagan más vulnerables porque rompen los esquemas sociales de protección/control por los varones y la jerarquía familiar. Las mujeres que migran transgreden el mandato sobre el cuidado de las familias que pesa sobre ellas y se 
les disciplina por ello. Ellas se exponen a un "castigo" que puede ser anónimo, ya que cualquier hombre puede atribuirse el papel de encarnar la autoridad cuestionada: "Todos los hombres son acosadores potenciales, los compañeros de viaje, el personal del tren, las autoridades, los asaltantes, los secuestradores, los polleros. Es evidente que las posibilidades de escaparse a una violación son muy escasas" (Castro, 2010: 125). El 24\% de las

${ }^{12}$ El trabajo de investigación de Médicos Sin Fronteras durante 2015-2016 de registra que casi un tercio de las mujeres migrantes centroamericaas encuestadas habían sufrido abusos sexuales durante el viaje por México, así como el 17\% de hombres (2017: 5 12).

mujeres migrantes es víctima de violencia sexual durante el tránsito por México, y los transexuales lo son en un 50\% (Díaz y Kuhner, 2016: 86). ${ }^{12}$ Los riesgos para su salud sexual y reproductiva con la exposición a contraer VIH o enfermedades de transmisión sexual o a embarazarse son obvios, también los traumas que implica "en la capacidad de llevar una vida laboral y social sana en el país de destino" (Díaz y Kuhner, 2014: 88).

Por esto las mujeres tienden a viajar de forma más clandestina que los hombres, como los niños, tienen un guía, coyote, traficante, que les acompaña y que, por tratarse de sujetos más "vulnerables", les cobra más por el "trabajo". Se estima que hasta un $70 \%$ de las mujeres migrantes podrían haber contratado

${ }^{13}$ Según EMIF Sur, en 2010 sólo el 14\% de las personas deportadas por México y el $10 \%$ de los deportados de EEUU utilizaron el tren de carga; y según Médicos Sin Fronteras, atendiendo cerca de las vías en el centro sur de México, reportan en el 2013 que el $12 \%$ de las personas viajando en el tren serían mujeres (Díazy Kuhner, 2014: 63). a un traficante para pasar México (Díaz y Kuhner, 2014: 79). Cruzan México combinando camiones, tráileres o en carro, a veces cargando documentación falsa, ellas apenas viajan en el ferrocarril y por ello llegan en menor número a los albergues de migrantes. ${ }^{13}$ 
Pagar un coyote o guía no es garantía, hace tiempo que el tráfico de personas se ha visto simbiotizado con las bandas criminales y los cárteles de la droga que, en un acecho constante, imponen sus violentos códigos al controlar los territorios de paso -de personas migrantes y de droga- y ampliar sus negocios sobre los cuerpos con los secuestros, la trata de personas o sexual y el esclavismo laboral. Su cuerpo es moneda de cambio y en el sur de México, el periodista Óscar Martínez (2010: 84) recoge que se denomina "cuerpomátic" en relación a una tarjeta de crédito.

Hay algunas que escogen un hombre como pareja coyuntural que las "proteja" en el camino, o bien a algún trailero, a cambio de sus servicios sexuales y "domésticos": les prepararan la comida, lavaran sus ropas, los cuidan. En la liminalidad del tránsito migratorio se acentúan los roles de las mujeres de servicio y cuidado y:

se enfrentan a una situación de autonomía limitada por la falta de recursos económicos, capital simbólico y capital social, de modo que las relaciones de género se vuelven más ambiguas y muchos hombres esperan que los favores se paguen con sexo (Willers, 2016: 181).

Es importante dimensionar la incidencia de la violencia sexual sobre las migrantes, quienes resultan "una diversión" hasta para los vecinos del camino (Martínez, 2010: 52). Cuando son víctimas de secuestro, ellas son obligadas a participar en todo tipo de servicio sexual, o doméstico, o ser objeto de trata. 
Ante la dificultad del viaje, o por el hecho mismo de huir por supervivencia, las mujeres tienden más que los hombres a tratar de asentarse en el camino ante una oportunidad laboral o al encontrar una pareja, aun cuando pueda tratarse de un proceso no concluso. Las mujeres, en su necesidad, se introducen en los segmentos del mercado del trabajo segregado por sexo más marginales, estigmatizados y con condiciones de explotación extrema. Algunas se ven atrapadas en las redes de trata y en el comercio del sexo o lo toman como empleo. Otras se dedican al trabajo doméstico, en comedores, en talleres y maquilas, pero es difícil diferenciar en estos escenarios de precariedad las situaciones de tránsito y de estadía. Muchas veces se confunden y se traslapan (Castro, 2010: 34).

La sucesión de violencias en el tránsito tiene consecuencias sobre las personas que lo intentan. Entre otros efectos de las extremas experiencias para todos los migrantes se produce la naturalización del sufrimiento y el quiebre de los órdenes normativos -ya dañados desde su origen-. En el caso de las mujeres, la experiencia migratoria

hace explícita la contradicción entre los valores, modelos y mandatos dominantes respecto a femineidad, moral, sexualidad, y las necesidades vitales de las mujeres... En otros términos, la construcción de estrategias de sobrevivencia y de resistencia, la necesidad de defender el proyecto migratorio y el proyecto de vida, entrelazados, ponen en entredicho los valores y mandatos dominantes interiorizados (Castro, 2010: 133). 
También las mujeres interiorizan la criminalización de su condición migrante: "las mujeres no identificaron la extorsión como un tipo de delito, como resultado de la corrupción y la impunidad imperante, sino como pagos necesarios para adquirir su derecho de paso" (Díaz y Kuhner, 2014: 77). También suelen recorrer el trayecto mexicano con inyecciones anticonceptivas u ocultándose con una vestimenta masculina.

Se hace complejo documentar los casos porque ellas no se detienen a denunciar, es más urgente cumplir con el envío de remesas (Díaz y Kuhner, 2014: 87). Las mujeres se resisten a buscar justicia y a entrar en la ficción del Estado que protege sin proteger, en la ineficiencia de procesos alargados y revictimizadores que exigen una permanencia que es insostenible en sus casos. ${ }^{14} \mathrm{Y}$, de nuevo, habría que ver en cada situación los matices entre violencias feminicidas y, si alcanzasen a serlo, femigenocidas.

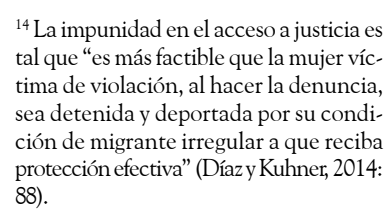

${ }^{14}$ La impunidad en el acceso a justicia es tal que "es más factible que la mujer víctima de violación, al hacer la denuncia, sea detenida y deportada por su condición de migrante irregular a que reciba protección efectiva" (Díaz y Kuhner, 2014: 88).

\section{Las mujeres en paso por el centro de atención al migrante}

\section{de Guadalajara}

Las mujeres que son atendidas psicológicamente en el Centro de Atención al Migrante FM4 en Guadalajara -CAM- dentro de un programa del Instituto Municipal de la Mujer están de paso, de ahí que se trata de seguimientos breves e intensivos. Los datos se refieren a los meses de abril a noviembre de 2016 cuando arribaron 145 


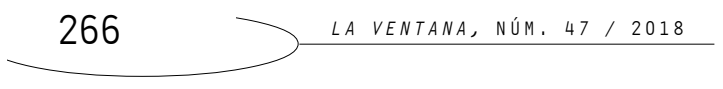

mujeres al CAMde ellas, 77 recibieron asistencia por parte del Programa.

\section{El corredor ferroviario del Pacífico y FM4}

El Centro de Atención al Migrante se ubica en la céntrica calle Calderón de la Barca, a la par de las vías del tren. Funciona en esta sede desde octubre de 2015. Es una estancia de día donde se ofrecen tres comidas diarias, instalaciones para aseo

${ }^{15}$ En diciembre de 2016 se inauguró la sección de albergue en el CAM. Con esto se abre una nueva etapa en el servicio a las personas migrantes pues ahora pueden pernoctar en un lugar seguro, esto no era posible cuando se hicieron las observaciones que presentamos. personal, lavado de ropa y descanso. Se cuenta con servicios de atención médica, atención psicosocial y asesoría jurídica para casos especiales. ${ }^{15}$ La mayoría de quienes llegan lo hacen en el tren de carga.

La Zona Metropolitana de Guadalajara es un área estratégica de confluencia de población y de producción, con industrias, comercio y servicios que se encuentra a la mitad del trayecto migratorio por el corredor ferroviario del Pacífico. La migración en tránsito es un tema relativamente reciente en las dinámicas de la ciudad porque no ha sido una vía privilegiada para los migrantes hasta la instalación del grupo criminal de Los Zetas y la violencia implacable en el este de México.

\section{Mujeres migrantes en el CAM perfil básico}

Son pocas las mujeres que llegan a Guadalajara pero, después de un largo y peligroso recorrido, encuentran un descanso, aún con- 
servan cierta inocencia y mucha esperanza. Como los migrantes masculinos, las mujeres son hondureñas en tres cuartas partes, y el siguiente grupo nacional es el de las mexicanas que suponen 13 casos (18\%). Antes de aventarse a salir al camino rumbo al Norte, en sus países de origen muchas de ellas tenían pequeñas ventas de pan, churritos, tortillas, café, ropa. Otras trabajaban en casas, en fábricas de puros, como guardias de seguridad, y hay quienes se identifican como amas de casa.

El abanico de edades es grande, pero el grupo de 18 a 29 años supone el 58\%, las menores de edad son cinco - una de ellas apenas tiene 14 años-, y treintañeras la cuarta parte. Con más de 40 años son siete casos, con mujeres de hasta 61 y 64 años.

Llama la atención que tienen pocas experiencias de deportaciones y, por tanto, de varios tránsitos por México, son "primerizas" en un elevado $84 \%$. Esto es importante porque se puede pensar en una migración más desesperada y un tránsito más precarizado. Hay unas pocas, cuatro, que tienen experiencias en Estados Unidos, una de ellas llegó a pasar 11 años allí antes de que la deportaran. Y hay otros cuatro casos que tienen entre dos y cuatro intentos fracasados de pasar.

La gran mayoría de las mujeres se encuentra en tránsito hacia Estados Unidos, pero hay algunas tratando de obtener refugio o asilo, otras que están de retorno, y unas pocas se encuentran en situación de calle. Llama la atención que manejen una fuerte ideología del retorno a pesar de que puedan huir por violencia: su objetivo es mandar dinero cuanto antes y conseguir una casa para regresar. 


\section{Acompañamiento en el camino}

Las mujeres vienen con redes de hombres (65\%) con las que se han sentido seguras, bien con una pareja acompañante que han conocido en el camino o en grupos variados, con hermanos/as, cuñados/ as, primos, u otros. Sin embargo, el resto expresaron que iban solas, aunque ocasionalmente se pueden integrar con algún grupo que va de camino. El acompañamiento en el tránsito es algo coyuntural y precario, no se viaja seguido con un mismo grupo ni con una misma persona.

Hay ocho mujeres que vienen con niños. Así es el caso de una pareja con su hija de tres años que salieron después de que les balacearan en El Salvador. Ellos han conseguido una visa humanitaria en Tenosique y solicitarán la reunificación familiar para poder traer al resto de hijos que dejaron allí (luego desistieron de los trámites).

A veces viajan en el tren, otras en autobús. Algunas reciben apoyo de familiares y viajan con coyote o guía. En este último caso no resulta fácil distinguir cuándo se trata de servicio contratado o de un traslado forzado, pues no siempre están dispuestas a denunciar a los agresores que las llevan por amenaza. De hecho se detectaron tres casos de mujeres que mostraban indicios de ser víctimas de trata e incluso dos jóvenes hondureñas que vivían en el norte de México y parecían enganchadoras para algún tipo de tráfico de personas o sexual. 
En el caso de quienes van con parejas, esto tampoco supone viajar "tranquilas" ya que ellos suelen comportarse como hombres celosos y golpeadores. Aquí de nuevo las mujeres tienen estos hechos naturalizados, incluso no reconocen ni identifican la violación con una pareja estable como violencia. Yonia, con apenas 19 años, se ve violentada por su pareja porque el bebé que espera no es de él, de tal forma que insiste en querer darlo en adopción. Otras nos descubren el abandono que pueden sufrir. Juana, de 22 años, es una hondureña cuyo tránsito se ha alargado porque su pareja la dejó en el camino con un bebé de pocos meses. Mientras a Pati, también hondureña de 26 años, ha sido su hermano quien la ha dejado, aunque ahora se mueve con su primo. Abandonos son también los que están detrás de casos de mujeres en situación de calle, como el de una guatemalteca ya mayor y establecida en las calles de Guadalajara, que expone que no pudo seguir sus trámites de regularización al no encontrar apoyo en su familia.

Una de las estrategias de las mujeres para pasar a salvo en el trayecto es el vestirse como hombres o con prendas más sueltas. Un día llegó una chica vestida de muchacho con cuatro hombres que le daban protección a cambio de que ella les comprara comida cada parada del tren. Ellos sí sabían que era mujer, los demás no.

Cuando vienen con parejas no suelen tener un papel protagónico, se atienen a "lo que el hombre diga". Si vienen solas su capacidad de decisión es mayor y contemplan sus redes de apoyo, de vínculos, de estrategias. Vinieron tres mujeres y dos hombres homosexuales que viajaban en grupo, seguían a la líder que había estado en pri- 
sión y había hecho el camino ya como cinco veces. Lo conocía y no requería hombres.

\section{Violencias}

Violenta es la situación de recurrir a un albergue al tener que dejar atrás sus mundos de vida. Pero además el registro de modalidades de violencias sufridas por las mujeres atendidas en FM4 parecen un rosario interminable: psicológica, física, intrafamiliar, violaciones, asaltos, abandonos, humillaciones. De las 77 mujeres, 48, que son casi dos terceras partes, comparten haber sufrido en su vida algún tipo de violencia. Doce de ellas refirieron haber sido violadas, sea en su lugar de origen o en Estados Unidos; nueve lo fueron en el tránsito migratorio.

Muchas migrantes denominan "lugares diabólicos" a los espacios donde sufrieron experiencias traumáticas como Tenosique o Chontalpa en Tabasco, lugares de violaciones por garroteros -operadores del tren-, mareros u otros. Se han dado varios testimonios de violaciones tumultuarias. Una vez llegó al CAM una mujer que no quería estar cerca de los hombres, no volteaba a ver a nadie, estaba llorando y se refugió en la cocina, rehuía el contacto, aparentaba estrés postraumático. Más tarde se reconstruyó que esta joven salvadoreña de 21 años había sufrido dos violaciones, una de ellas por tres personas. La derivaron a Casa de Medio Camino para mujeres víctimas de violencia, le dieron terapias, tratamiento en los dientes desechos por la droga e inició su proceso jurídico. Ter- 
minó desistiendo y se regresó a El Salvador, donde había dejado a sus hijos con su madre, al saber que su marido exmarero se los había quitado a ésta recientemente.

Otra joven de Honduras, de 21 años también, fue violada dos veces, una por una sola persona y después por cinco en Tabasco. El primero la forzó a hacer sexo oral, y a su vez forzaron a otra mujer al lado de ella, a esta otra chica la desnudaron, la violaron y la dejaron tirada. En otras dos narraciones de abusos se encontró que había otras mujeres en la misma situación a la vez que ellas.

En la historia de la siguiente violación es importante observar sus repercusiones al condicionar la vida de esta persona. Esta hondureña de 17 años quedó de bailarina exótica en un table dance en Tabasco porque un militar la abusó antes de entrar al negocio. Ella dice "no me arrepiento" porque considera que en su momento esta ocupación la ayudó a salir adelante. Tiene 5 hijos, tres de ellos mexicanos. Se quedó viviendo en Tabasco muchos años y después se regresó a Honduras. Ahora todos los chicos están en Honduras, incluso los nacidos en México, y como ella tiene papeles mexicanos, intentará el cruce.

En el caso de los transexuales y homosexuales la violencia es aún más extrema (ver Winton, 2016). De los casos atendidos en FM4 no había ninguna que no hubiera tenido experiencias de abusos sexuales. Si la mayoría de las mujeres ya tienen una lucha desde el origen con la violencia sexual y psicológica que han sufrido, las transexuales tienen una violencia sexual y psicológica exponencial. En sus casos, por las largas experiencias de discrimi- 


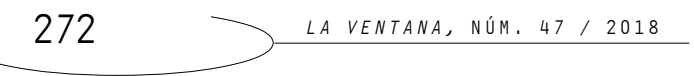

nación en todo lugar donde estén, se da una conciencia más fuerte de lo que son, configurando de forma positiva su autopercepción por el simple hecho de salir de casa.

\section{Madres-hijos}

Prácticamente todas son madres. Esto hace pensar si están migrando y huyendo por ello, por ser madres, con el abandono social, institucional, estatal, sistémico, que estos hechos desnudan. Tienen una gran vinculación con los hijos que, por diferentes motivos y circunstancias, las hacen movilizarse y pasar fronteras dejándolos "encargados". Otras los traen consigo -ocho casos-, como una migrante que venía con su pareja, dos niños y embarazada de ocho meses. Esto implica que nos encontramos ante un grupo familiar y nos hace suponer que algo grave está ocurriendo para que viajen así. Son muchas las historias donde se observa la fuerza de un contexto insostenible de la vida cotidiana.

Los hijos son claves en tomar la iniciativa de salir, pero también en la de volver. Valeria, de 18 años, mexicana, regresaba porque se encontraba embarazada. Lupe es una señora de 61 años, que residia en Estados Unidos -13 años en Massachussets-. Se arriesgó por llegar a enterrar a su hijo asesinado en El Salvador. Los 20 días que pasó allí fueron suficientes para saber que no era su lugar, así que regresa al norte sola y en el tren. Bety, hondureña de 29 años, salió de allí por amenazas de las maras pero decidió volver porque un hijo suyo había enfermado. Bien acompañada y atendida por tres 
primos, y pese al peligro que corre, no aguantó separarse de sus 4 hijos: "me duele dejar a mis hijos". Ahora su estrategia será cambiarse de pueblo. $\mathrm{O}$, como vimos, la salvadoreña que optó retornar para recuperar a sus hijos que su marido marero había arrebatado a su madre con quien los había dejado.

Embarazadas son ocho. Una de ellas tenía ocho meses y dos semanas y venía con una anemia grave, se acompañaba con una persona que decía que era el papá del niño y que la controlaba con la mirada, no podía hablar. Estaba muy delgada, tenía 23 años pero parecía de 15 . Venían en tren, con su pareja y otra chica. Parecía que el hombre las estaba prostituyendo. Se le explicó que estaba en riesgo su vida y ella decidió irse. Además encontramos a Heidi, embarazada, con un hijo de 3 años y con su esposo, y a Dolores Guadalupe, que venía con su niña también de 3 años. Ambas se encuentran e interaccionan porque los niños juegan juntos. Las dos se ven deprimidas, tristes y desesperadas, pese a que los hombres parecían tratarlas amables y serviciales. Mientras Selena, también embarazada y con un niño, tenía que aguantar un trato humillante de su esposo. Su historia era dura: violada por un hermano a los siete años, su esposo la maltrataba y la obligaba a acompañarlo a Estados Unidos.

\section{Experiencias de asentamientos y deportación}

Hay algunas mujeres que tienen tiempos largos de clandestinaje en México. Quizás esto tiene que ver con el asentamiento por el 
que tienden a optar que, sin embargo, es muy precario. Estos intentos de generar una nueva vida no necesariamente son exitosos. Por ejemplo Mirta, hondureña de 37 años, trabajó durante un tiempo en un bar en Tabasco con su hija. En un momento su hija se enamoró y se fue a la Ciudad de México, y ahora está probando suerte hacia el Norte con su hermano, quien es agresivo con ella.

Entre las 64 mujeres que no son mexicanas, hay 10 con diferentes maneras de estancia en México más o menos larga: bien porque son solicitantes de asilo y desistieron; porque se sospecha sean víctimas o enganchadoras de alguna trata; o bien hay tres mujeres que vivieron y se establecieron en estados de México, incluso tuvieron hijos aquí, y por diferentes circunstancias tuvieron que volver al tránsito, al cambio, a la expulsión. Una de ellas, hondureña, vivió en Tabasco por cuatro años, su marido era violento y estaba en el narcotráfico, la amenazó de muerte y la hizo huir; mientras la suegra se ha quedado con las niñas, que además están sin registrar. Tiene 24 años y levantó denuncia, pero en la huida será difícil darle seguimiento a esta.

La indeterminación de los procesos de las mujeres continúa, y otro hoyo de desánimo desarticulador se produce si hay deportación. De pronto se ven sumidas de nuevo en un espacio donde el crimen se ha implantado y con él las extorsiones, las ejecuciones o las violaciones en las colonias, y donde no hay un mercado laboral accesible. Las dificultades y la presión se multiplican hacia migrantes recién regresados: imaginando que traen dólares, las maras o pan- 
dillas piden cuotas tan altas que las personas no

${ }^{16}$ La cuota, renta, impuesto o extorsión por "protección", es una apropiación de pueden cubrirlas y son forzadas a huir otra vez (Willers, 2016). ${ }^{16}$

Hoy el proceso de tránsito no se deja describir la atribución del Estado que es un flagelo en toda Centroamérica y partes de México. El nivel de descapitalización que provoca en economías tan precarias es un motivo fundamental de salida, ya que el castigo por su incumplimiento al no como un viaje unidireccional en un tiempo definido, sino más bien como un camino que implica vapagar es la muerte y, si ésta no es ejecutada en la persona designada, se realiza sobre otro miembro de la familia. Es una muy violenta forma de sobrevivencia rias idas y vueltas. Incluso, puede tener fases de parasitaria de las pandillas a costa de los asentamiento temporal que a veces se convierte en trabajadores de sectores populares.

definitivo. Y este escape a través de México para las personas sin recursos es como una cacería entre los controles fronterizos y la connivencia con el crimen en todas sus dimensiones, lo que les deja en el "caminando" como futuro. Como estamos viendo las mujeres migrantes

muchas veces no encuentran mayor estabilidad en los lugares de llegada para realizar los planes que tenían al emprender el camino. Debido a las dificultades que experimentan, el proceso no termina en un punto geográfico: volver a migrar sigue siendo una opción para enfrentar las situaciones de adversidad (Willers, 2016: 183-184).

\section{"No somos animales"}

A las mujeres en el CAM les gusta pasar el tiempo coloreando mandalas o dibujando. Esto les permite la capacidad de volver a sí mismas como alguien inocente porque se reconocen tan violentadas que 
17 "La angustia y estrés que sufren los migrantes y refugiados, tanto en sus países de origen como en la ruta, los hace muy vulnerables a la ansiedad, la depresión y el estrés postraumático" (MSF, 2017: 16). Las mujeres manifiestan en un $59 \%$ síntomas de depresión y en un $48 \%$ síntomas de ansiedad, porcentajes más elevados que entre los hombres. Por otro lado, la tasa de estrés postraumático $(15,4)$ en la población migrante se encuentra cerca de la que se produce en poblaciones afectadas por un conflicto. La normal se encuentra entre el 0,3 y el 6,1\% (Médicos Sin Fronteras, 2017: 17). esa manera de expresarse simple y sencilla les baja el estrés. Es dejar pensar por un momento que tienen que estar alertas. ${ }^{17}$

Se induce a las mujeres a escribir, se les dice que es importante dar a conocer quiénes son las mujeres migrantes en la población mexicana, que otras sepan que también hay mujeres que están luchando como ellas. Y anotan: "Díganles que no somos animales, que nos traten bien, que nos apoyen". Las mujeres adoptan con ello una posición política, quieren socializar su testimonio de sobrevivencia ante lo abrumador y lo excesivo de lo vivido que desborda los marcos de referencia, que no se pierda la experiencia ni su ser moral y que sea público. Es raro que se nieguen a compartir su historia. Si hay una historia que se quiere compartir, hay una lucha social y una exigencia de justicia aún sin querer tomar los casi imposibles caminos de la "legalidad".

Escriben cartas para las futuras migrantes desde una fe genuina llamando a orar y pedir a Dios que es el único que puede ayudarlas. El sentido religioso es una constante básica: Dios es el que da protección, la luz en el camino, "todo se puede lograr luchando y agarrada de la mano de nuestro Señor..." Pero el contenido de las mismas también es de ánimo y de exaltación de su valentía como mujeres: "Soy una mujer fuerte y este camino no es para andar yo sola".

Entre las inquietudes que nos dejan estas 77 mujeres se encuentran los casos de núcleos familiares. Este hecho se tiende a 
interpretar como una estrategia para aprovechar las supuestas ventajas que la ley migratoria pudiera conceder a mujeres con menores si llegan a pisar territorio norteamericano. Se analiza menos desde el tratarse de una expulsión que no solo afecta ya a los miembros masculinos sino a mujeres y a familias completas aventadas al desarraigo y al abandono.

También vemos importante el seguimiento a las mujeres que han intentado asentarse en México y, sin embargo, se ven de vuelta en el transitar - uno de los casos indicaba violencias y abusos de parte de los convivientes mexicanos. Es decir, estamos ante asentamientos precarios que pueden derivar en situaciones de calle haciendo que estas mujeres queden en la indistinción entre la migración, el tránsito alargado y la calle.

Una discusión reiterada entre quienes atienden la situación de las mujeres centroamericanas en tránsito por México se refiere a sus ambivalencias en cuanto a si esta experiencia supone o no empoderamiento de parte de las mujeres. Para algunos, las mujeres acumulan experiencias que las fortalecen y van adquiriendo grados de autonomía económica, emocional, vital (Castro, 2010: 108). Este es un tema intrincado porque la posibilidad de autonomía no es definitiva ni total, hay que calibrar esas opciones que tienen de alcanzar sus aspiraciones en un mundo con todo en contra, los costos parecen ser muy altos y no contamos con sus propias valoraciones.

Una tesis que habría que comprobar, relacionada con el punto anterior, remite al alto número de mujeres en su primera experiencia de cruzar México. Por un lado, ello nos habla de una migración 
más desesperada para las mujeres que, en un contexto que cosifica los cuerpos y precariza sus experiencias, se ven impulsadas a salir por sus medios - sin alcanzar a pagar a un coyote- y desde su exposición, incluso la de sus hijos si van con ellos o embarazadas.

Todas estas mujeres despedidas en la diáspora masiva de centroamericanos y del destino de ser madresposas en un ámbito doméstico, ahora tienen que tomar también los papeles masculinos, ser madre-padres. Por otro lado hay que pensar si no puede estar dándose al mismo tiempo una rebelión ante la masculinidad violenta que se habría exacerbado entre los miembros que rodean a las mujeres en sus lugares de origen con el capitalismo gore. Ellas reaccionan saliendo y quizás entrando en un proceso de reconfiguración como mujeres. Las resistencias, contradicciones, ambivalencias que recorren todas las narrativas nos impiden la certeza, pero por las actitudes que muestran se pueden estar dando caminos iliberadores? que no imaginamos.

Con el repaso de situaciones vistas, los marcos teórico contextuales que propusimos en el inicio tienen sentido pero no son suficientes. Sentimos que es preciso acercarse más a estas mujeres en fuga y a los contextos sociopolíticos y culturales de los que surgen y tener presente que la violencia del desplazamiento está erosionando el sentido de lugar y de lo social, mutando las experiencias de género, comunidad, trabajo, amistad, cuidado, familia y generando otras subjetividades. Estos flashes que ofrecimos de mujeres en el desplazamiento forzado invitan a reconocer su capacidad de desafío y lucha por la vida. Elisa García Mingo (2015: 
184), se refiere a las mujeres del Congo como cuerpos sociales que han recibido una enorme violencia sexual desde 1996. La autora cita a Didier Fassin quien considera que: "la supervivencia es la vida más allá de la vida, más vida que la vida (...) no es sólo continuar viviendo, sino vivir más intensamente".

Esperamos que esta exposición de efectos de los dispositivos bionecropolíticos sobre las mujeres centroamericanas en tránsito por México provoque al menos la sensibilización y el posicionamiento ante estas realidades.

\section{Bibliografía}

CARCEdo, A. (coord.). (2010). No olvidamos, ni aceptamos: Feminicidio en Centroamérica 2000-2006. San José de Costa Rica: Cefemina y Horizons.

Castro O. A. (coord.). (2010). Mujeres transmigrantes. México: Centro de Estudios Sociales y Culturales Antonio de Montesinos e Instituto de Derechos Humanos de la Universidad Iberoamericana de Puebla.

Colectivo de Apoyo para Personas Migrantes, A.C. (2015). Miradas migrantes. Las mujeres en la migración por México. México: COAMI INDESOL.

DíAz, G. y KuHner, G. (2014). Un viaje sin rastros. Mujeres migrantes que transitan por México en situación irregular. México: H. Cámara de Diputados, LXII Legislatura e Instituto para las Mujeres en la Migración 
A. C.

Foucault, M. (2007). El nacimiento de la biopolítica. México: FCE.

GARCíA, E. (2015). Cuando los cuerpos hablan. La corporalidad en las narraciones sobre violencia sexual en las guerras de República Democrática del Congo. Revista de Dialectología y Tradiciones Populares, vol. LXX, no 1, enero-junio 2015, pp 161-186.

LAGARDE, M. (2008). Antropología, feminismo y política: violencia feminicida y derechos humanos de las mujeres. En Bullen y Díez Mintegui, (coord.), Retos teóricos y nuevas prácticas. España: Ankulegi.

MARTínez, O. (2010). Los migrantes que no importan: en el camino con los centroamericanos indocumentados en México. México: Sur, Oaxaca.

Mbembe, A. (2011). Necropolítica. España: Editorial Melusina.

Médicos Sin Fronteras. (2017). Forzados a huir del Triángulo Norte de Centroamérica. Una crisis humanitaria olvidada. Informe mayo 2017. Ciudad de México / Nueva York / Madrid. Disponible en: http:// www.msf.mx/sites/mexico/files/attachments/msf_forzados-a-huirdel-triangulo-norte-de-centroamerica.pdf (consultado el 31/05/ 2017)

Peutz, N. y De Genova, N. (ed). (2010). Introduction. En Nicholas De Genova y Nathalie Peutz (ed.) The Deportation Regime: Sovereignty, Space, and the Freedom of Movement. Durham and London: Duke University Press.

Segato, R. (2016). La guerra contra las mujeres. España: Traficantes de Sueños. 
VAlENCIA, S. (2010). Capitalismo gore. España: Editorial Melusina.

VArela, A. (2017). "La trinidad perversa de la que huyen las fugitivas centroamericanas: violencia feminicida, violencia de estado y violencia de mercado". Debate feminista, 53, pp 1-17.

WiLlers, S. (2016). Migración y violencia: las experiencias de mujeres migrantes centroamericanas en tránsito por México. Sociológica, año 31, número 89, septiembre-diciembre de 2016, pp. 163-195

WinTON, A. (2016). Entre fronteras. Un estudio exploratorio sobre diversidad sexual y movilidad en la Frontera Sur de México. México: ACNUR, ECOSUR, Una mano amiga en lucha contra el SIDA A.C. 